
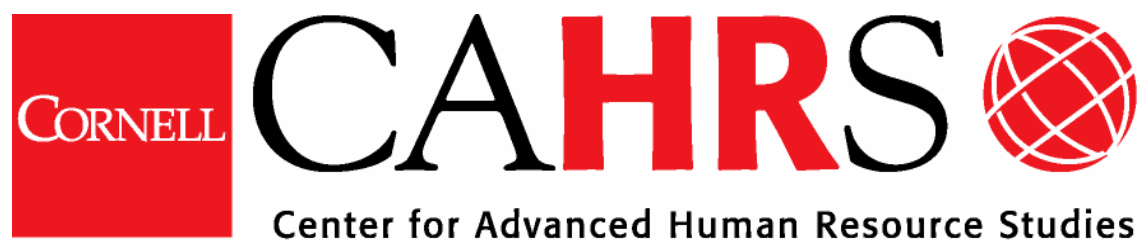

Center for Advanced Human Resource Studies

CAHRS / Cornell University 187 Ives Hall

Ithaca, NY 14853-3901 USA

Tel. 607 255-9358

www.ilr.cornell.edu/CAHRS/

Worhing Paper Serleg

\title{
Toward a Strategic Human Resource Management Model of High Reliability Organization Performance
}

Jeff Ericksen

Lee Dyer

Working Paper 04 - 02

CORNELL ilr School of Industrial and Labor Relations 


\title{
Toward A Strategic Human Resource Management Model of High Reliability Organization Performance
}

\author{
Jeff Ericksen \\ School of Industrial and Labor Relations (ILR) \\ Cornell University \\ Ithaca, NY 14853 \\ Tel: (518) 234-9811 \\ Fax: (607) 255-1836 \\ E-mail: gae1@Cornell.edu \\ Lee Dyer \\ School of Industrial and Labor Relations (ILR) \\ Cornell University \\ Ithaca, NY 14853 \\ Tel: (607) 255-8805 \\ Fax: (607) 255-1836 \\ E-mail: Idd3@Cornell.edu
}

March 2004

http://www.ilr.cornell.edu/cahrs

This paper has not undergone formal review or approval of the faculty of the ILR School. It is intended to make results of Center research available to others interested in preliminary form to encourage discussion and suggestions.

Most (if not all) of the CAHRS Working Papers are available for reading at the Catherwood Library. For information on what's available link to the Cornell Library Catalog:

http://catalog.library.cornell.edu if you wish. 


\begin{abstract}
In this article, we extend strategic human resource management (SHRM) thinking to theory and research on high reliability organizations (HROs) using a behavioral approach. After considering the viability of reliability as an organizational performance indicator, we identify a set of eight reliability-oriented employee behaviors (ROEBs) likely to foster organizational reliability and suggest that they are especially valuable to reliability seeking organizations that operate under "trying conditions". We then develop a reliability-enhancing human resource strategy (REHRS) likely to facilitate the manifestation of these ROEBs. We conclude that the behavioral approach offers SHRM scholars an opportunity to explain how people contribute to specific organizational goals in specific contexts and, in turn, to identify human resource strategies that extend the general high performance human resource strategy (HPHRS) in new and important ways.
\end{abstract}

Funding for this research was provided by the Center for Advanced Human Resource Studies (CAHRS) and the Benjamin Miller Scholarship Fund, both of which are affiliated with the ILR School, Cornell University 


\section{Toward A Strategic Human Resource Management Model Of High Reliability Organization Performance}

Strategic human resource management (SHRM) is concerned with the contributions human resource strategies make to organizational effectiveness, and the ways in which these contributions are achieved. While theory and research have addressed both issues, much of the initial work focused on the former. This consisted primarily of large-scale survey studies in which various measures of human resource activities or programs on the one hand were statistically related to one or more measures of firm financial performance (e.g., return on investment, return on assets, and stock values) on the other (for recent reviews see Boxall \& Purcell, 2000 and Delery \& Shaw, 2001). Although plagued by some rather serious conceptual and methodological shortcomings, collectively these studies produced results credible and positive enough to keep SHRM scholars intrigued and pushing forward (Wright \& Gardner, 2002).

Over time, as the field's focus has shifted from "show what" to "show how" (Dyer \& Shafer, 1999), SHRM scholars adopted a contingency (or occasionally configurational) perspective, leading theorists and researchers into the domain of fit, or alignment. Here, fit comes in two forms. One is vertical, or the degree of alignment between (a) components of a firm's human resource strategy and (b) core features of its business strategy. The other is horizontal fit, or the degree of alignment among components of a firm's business strategy (typically activities or programs such as selection, training, and compensation). Conceptually, the two notions of fit have been used to derive normative models to show how intuitively derived typologies of human resource strategy should be paired with similarly derived typologies of business strategy to maximize firm performance (e.g., Dyer \& Holder, 1988). Empirically, the contingency (or configurational) perspective has informed a series of empirical studies designed to determine whether business units that had achieved vertical and horizontal fit performed 
better than those that had not (e.g., Arthur, 1992; Delery \& Doty, 1996; Ichniowski, Shaw \& Prennushi, 1997; MacDuffie, 1995; Youndt, Snell, Dean \& Lepak, 1996). In general, these studies have produced, at best, mixed support (Wright \& Sherman, 1999). As a result some SHRM scholars have come to advocate a universalistic or "best practice" approach to human resource strategy; that is, to argue that a single high performance human resource strategy (HPHRS) enhances organizational effectiveness regardless of organizational goals, work systems, or context (Becker \& Huselid, 1998; Pfeffer, 1998).

Before definitive conclusions can be drawn, however, it is necessary to more fully explore the features and dynamics (e.g., employee behavioral patterns) occurring in the socalled "black box" between human resource activities and programs on the one hand and indicators of firm competitiveness and performance on the other (Becker \& Gerhart, 1996). Early SHRM scholars, for example, suggest that certain organizational goals require certain employee behaviors and that certain human resource strategies produce certain employee behaviors, and that the task of the human resource strategist is to uncover and test these linkages (Cappelli \& Singh, 1992; Schuler \& Jackson, 1987; see also Delery \& Shaw, 2001). This so-called behavioral approach to SHRM is conceptually appealing. It suggests that the extent to which a human resource strategy contributes to organizational performance depends (i.e., is contingent) on its capacity to foster desired employee behaviors. Despite its appeal, the behavioral approach has only rarely been employed (Delery \& Shaw, 2001; Wright \& Sherman, 1999; for an exception see Dyer \& Shafer, 1999, 2003). Thus, an opportunity exists to develop SHRM models using a behavioral approach.

Here we pursue this opportunity by taking a closer look at high reliability organizations (HROs). HROs strive to achieve virtually problem free performance under the most trying of circumstances. Examples of HROs include nuclear power generation plants, naval aircraft carriers, air traffic control systems, and hospital emergency centers. HROs provide a good setting in which to develop a behavioral model of SHRM for five reasons. First, their 
organizational goals are both unique and quite clear: to avoid disasters, breakdowns, errors, and the like. Second, prior HRO research suggests that people play a crucial role in helping organizations to achieve high reliability performance. Or, put in the negative, that inappropriate employee behavior tends to be a common cause of organizational failure. (Roberts and Bea [2001a], for example, note that as many as 80 percent of organizational failures involve misdirected employee action.) Third, the HRO literature is filled with case studies and other analyses that make it possible to extract an initial set of employee behaviors likely to foster high reliability. Fourth, HRO theory and research strongly suggests that context matters; in particular, that the presence of trying conditions (the complexity of the system, high levels of interdependence between and among people and technology, and external volatility) requires organizing systems (and, thus, employee behaviors) that differ substantially from those used in more stable settings. Finally, although no one to our knowledge has considered what an appropriate human resource strategy for HROs might look like, the HRO literature suffers no shortage of potential insights.

In this article we present a SHRM-based model of HRO performance that is simple and straightforward (see Figure 1). Nonetheless, we believe that our analysis contributes to the ongoing SHRM conversation in four ways. First, we point to organizational reliability as an ideal, system-level, employee-driven measure of firm performance that is absolutely critical for particular set of organizations. Second, we identify a set of reliability-oriented employee behaviors (ROEBs) likely to foster organizational reliability. These behaviors complement existing SHRM efforts to illuminate the "black box" using a behavioral approach. They also are HRO specific in the sense that they are likely to be more valuable for firms focused on reliability than for firms pursuing other performance outcomes. Third, we underscore the contingent nature of employee behavior by suggesting that ROEBs are more important for firms operating under trying conditions than for those working in more stable environments. We suggest that desirable employee behaviors depend not only on organizational goals but also on the 
environments in which firms operate. The implication of this argument, if true, is that future SHRM theory and research would benefit more from deeper and richer explorations into the settings and circumstances in which certain employee behaviors enhance organizational performance. Finally, we develop a set of human resource management principles likely to facilitate the manifestation of reliability-oriented behaviors. The reliability enhancing human resource strategy (REHRS) we present focuses on the organizing systems HROs use and, thus, (a) includes aspects of organizational infrastructure (i.e., organizational structure, technology, and processes) as well as human resource principles and activities, (b) emphasizes principles, and (c) is quite specific with respect to infrastructure features and human resource activities that comprise each principle. We suggest, therefore, that the REHRS is likely to be more beneficial for firms pursing reliability under trying conditions than is a more generic form of the HPHRS. Much SHRM theorizing begins with human resource strategy and then progressively works out toward firm performance. Employing a behavioral approach, of course, requires executing the pattern in reverse. The remainder of this article is thus organized as follows. We begin by discussing the viability of reliability as a performance indicator. Next, we identify a set of eight ROEBs that extant HRO theory and research suggest are critical antecedents of organizational reliability. Then, we consider the extent to which the relationship between ROEBs and organizational reliability is moderated by trying conditions. Finally, we develop six REHRS principles based on prior HRO and SHRM theory and research and assess them for vertical and horizontal fit. 
Figure 1

\section{Toward a SHRM Model of HRO Performance}

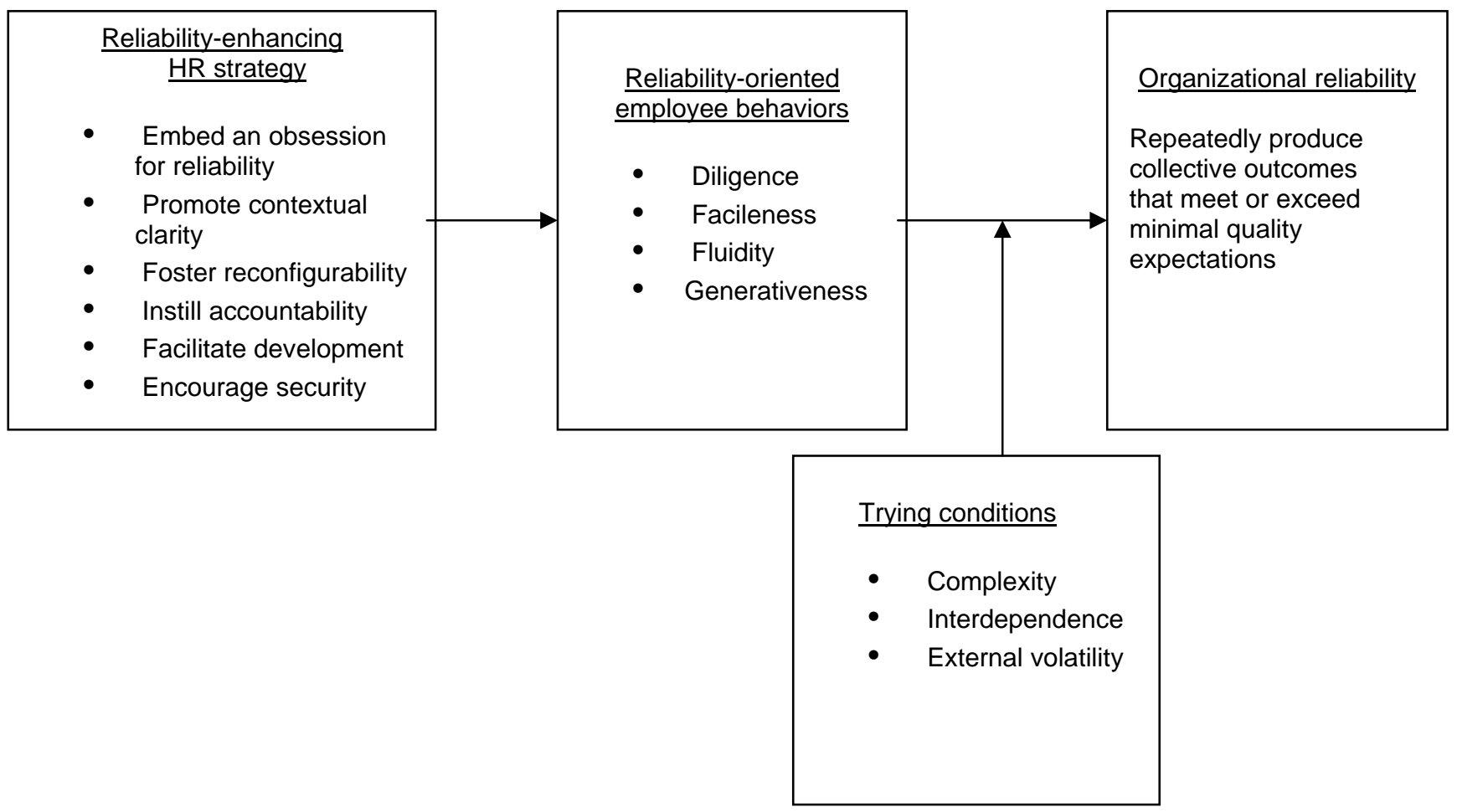

High Reliability Performance

Conceptualizing organizational reliability has historically been a controversial matter within the HRO literature. While few disagreed that reliability refers to an organization's "capacity to produce collective outcomes of a certain minimum quality repeatedly" (Hannan \& Freeman, 1984: 153), opinions bifurcated from there. Students of normal accident theory (NAT), on the one hand, suggested that there is no such thing as a reliable organization; that the question isn't whether reliability seeking organizations will fail, but rather when (e.g., Perrow, 1984). Students of HROs, one the other hand, argued it is possible for organizations to continually delay or even permanently defer the inevitable failures through effective organization 
(e.g., Roberts, 1990). Fortunately, "recent research on high reliability has moved beyond these extreme positions. It has embraced the idea of 'higher reliability' as a performance variable rather than reliability as a defining characteristic" (Schulman, 2001: 346; see also Creed, Stout, \& Roberts, 1993). But, while the notion of higher reliability is now theoretically justifiable, it has largely remained empirically under-explored. Investigations into organizational reliability primarily consist of case studies that examine the antecedents of effective action (e.g., Bigley \& Roberts, 2001; Roberts, 1990; Roberts, Stout, \& Halpern, 1994; Weick \& Roberts, 1993) or catastrophic failure (e.g., Perrow, 1984; Shrivastava, 1987; Vaughan, 1996; Weick, 1990, 1993) in reliability seeking organizations. While clearly insightful, these efforts treat reliability as a binary (success or failure) concept. The problem, according to Schulman (2001: 347), is that too much reliance on single case studies leads to "a danger of falling victim to a kind of evolutionary optimism that infers that because features have evolved in an organization that is surviving in a high-reliability niche, these features must contribute to its overall reliability". Aggregating findings across case studies is difficult because one quickly runs into the problem of too many variables and too few cases.

Operationalizing organizational performance has not been easy for SHRM scholars either. Firm-level performance indicators such as profitability (e.g., ROI and ROA), sales growth, and stock market value (e.g., Tobin's Q) have been most common despite their conceptual distance from human action. As a result, some have accused SHRM researchers of selecting performance measures on the basis of empirical convenience over conceptual veracity (Rogers \& Wright, 1998); others have called for future research to focus on intermediate, process-related performance measures that indicate how financial results are achieved (Becker \& Gerhart, 1996: 793); still others point to "a crying need for a few carefully selected, qualitatively oriented, intensive case studies to help clarify the nature of the variables and relationships" (Dyer \& Shafer, 2003: 8). 
Both the SHRM and HRO literatures would thus stand to benefit from a merging in thinking. The HRO literature could gain from theory-building exercises that treat reliability as relative and comparative and that summarize findings across the case studies and ready them for empirical test. SHRM theory and research, in turn, could profit from efforts that focus on organizational reliability as a critical process-based, yet theoretically driven, measure of organizational performance and that leverage the HRO literature's extensive case studies into how HROs' people contribute to high reliability. Attention now turns to the task of identifying these ROEBs.

\section{Reliability-Oriented Employee Behavior}

HRO research, conducted as it is by organization theorists, tends to focus on organizational structures, processes, and technologies (i.e., infrastructure) and employee mindsets as they key antecedents of high reliability performance. While numerous studies of organizational reliability suggest that employee behaviors often play a critical mediating role in the relationship between organizational infrastructure and employee mindset and organizational reliability, extant treatments of employee behaviors tend to be secondary, sporadic, and widely dispersed. Consider, for example, Weick's (1988) analysis of the gas leak at Union Carbide's Bhopal plant (see also Shrivasta, 1987). In the article, Weick points to decreased slack (i.e., organizational cost cutting efforts that led to lower facility maintenance and diligence) as the key cause of the disaster; hence, he concludes that "[a]s slack decreases, the technology becomes more complex, which means there are more places where a minor lapse can escalate just when there are more minor lapses occurring" (Weick, 1988: 313). But, what actually constituted "decreased slack" at the Bhopal plant? Weick, in passing, points to employee behaviors: to wit, "increased inattention, indifference, turnover, low cost improvisation, and working-to-rule" (1988:313). A behavioral approach to high reliability performance, of course, would involve paying significantly more attention to such ROEBs. Thus, a SHRM scholar examining Weick's analysis of the Bhopal case would likely conclude that ROEBs mediate the relationship between 
organizational infrastructure and organizational reliability. Or, more specifically, that decreased organizational slack reduces the quantity or quality of ROEBs (e.g., ascertaining and improvising) that foster reliable performance.

Despite the prominence of the behavioral approach in SHRM thinking, few empirical efforts have explicitly tested the mediating role of employee behaviors (Delery \& Shaw, 2001; Wright \& Sherman, 1999). Further, many of the behaviorally based theoretical models designed to guide future empirical efforts begin with human resource strategy and thus point to rather general employee behaviors such as turnover, pro-social, citizenship, effort, and so forth. On the positive side, such general behaviors are likely to lead to universal findings (i.e., commitment, citizenship, effort and the like foster organizational performance in many different organizational contexts - i.e., high technology start-ups, factories, etc. - and across many different organizational goals - i.e., growth, quality, productivity, etc.). The downside to such approaches, however, is that general behaviors, while perhaps necessary, are unlikely to be sufficient for many organizational goals.

As noted earlier, prior HRO case studies offer a good source in which to identify specific employee behaviors that drive a specific type of organizational performance. In the remainder of this section, then, we discuss eight ROEBs that the HRO literature suggests are crucial for reliable performance and organize them into four categories based on the underlying organizational capability involved.

\section{Diligence}

Diligence refers to an organization's capacity to anticipate or detect surprises early and without compromising routine operations. The goal is, at best, to foresee and forestall problems before they emerge or, at worst, to detect and locate problems quickly enough to act before they escalate. HROs are thus often described as being ever "thoughtful', "heedful", and "mindful" of the unexpected (Weick, Sutcliffe \& Obstfeld, 1999; Weick \& Roberts, 1993), their systems and 
people characterized as being more careful, critical, consistent, purposeful, attentive, studious, vigilant, and conscientious than are those of a typical organization (Roberts \& Bea, 2001a: 182). Such hyper-vigilance is, at least in part, the result of employees that continuously and effectively ascertain and communicate.

Ascertain. People in HROs are chronically on the lookout for the unexpected. They actively monitor and challenge each other's actions and thought processes to keep problems from occurring in the first place (Weick \& Sutcliffe, 2001). They continually anticipate and detect a large number and variety of problems, errors, failures, and surprises (Bierly \& Spender, 1995). As a result, perhaps counterintuitively, they make fewer mistakes and yet identify more problems than do less attentive workforces (Edmondson, 1996).

Communicate. People in HROs also communicate more or less continuously because they implicitly recognize that a direct relationship exists between the quantity of communication and reliable performance (LaPorte \& Consolini, 1993). They strive to avoid distortions and misunderstandings by conversing and corresponding a direct, clear, precise, and accurate manner. They report problems or failures immediately and candidly (Weick et. al., 1999). Finally, they go to great lengths to avoid what Weick (1990) refers to as "pluralistic ignorance" in which individuals are puzzled by what's going on but assume that no one else is. They never take for granted, for example, that they alone have lingering doubts about the wisdom of launching the Challenger space shuttle as scheduled (Vaughan, 1996), or that the captain realizes that another airplane is sitting in a dense cloud in the middle of his takeoff runway (Weick, 1990).

\section{Facileness}

When the unexpected strikes, HROs are facile in the sense that they are capable of quickly and easily switching from stable and routine activity to flexible and novel action and then back again. HROs immediately trigger substitute structures that forestall paralysis and panic 
and facilitate the bringing of problems under control. Often times, these alternate structures are slightly modified versions of well-planned and practiced response tactics (Bigley \& Roberts, 2001). Other times, they represent almost wholly emergent processes (Bourrier, 1996; Rochlin, 1989). In either case, facileness requires people to initiate and deploy, to know when and how to switch from one mode of organizing to the other.

Initiate. People in HROs initiate appropriate action to mitigate and rectify unexpected events. They take responsibility for problems (Weick et. al., 1999). When they get into situations they don't understand, they ask for help; they admit that they are in over their heads and they enlist outside assistance (Weick \& Sutcliffe, 2001). Finally, when necessary, they "call foul", shut down the system to keep problems from growing and escalating, and then mobilize an appropriate response (Roberts, 1990; Roberts, et. al., 1994).

Deploy. People in HROs also rapidly deploy. They switch tasks and roles with minimal time and effort so that help arrives where and when it is needed. They organize into ad hoc action groups and then dissolve as soon as the crisis is over (Rochlin, 1989). As a result, organizational expertise is rapidly pooled and mobilized around events that are impossible to anticipate.

\section{Fluidity}

Once organizational response tactics have been triggered and critical resources mobilized, HROs are remarkably fluid. That is, they exhibit the capacity to operate effectively in chaotic situations where traditional order has collapsed. This is no small thing. Many disasters have resulted from small system failures that amplify because human interaction breaks down in the ensuing chaos and people act less like a collective force and more like independent strangers (Weick, 1993; Reason, 1997; Shrivasta, 1987). People in HROs, by contrast, are collectively at their best in a crisis because they thrive when spontaneously coacting and improvising to face down emergencies (Weick \& Sutcliffe, 2001). 
Coact. Novel and complex problems require people with diverse talents and perspectives to coact or spontaneously collaborate -- to collectively attack the issues at hand with minimal wasted time and effort. Thus, people in HROs closely interact with one another to generate hypotheses about what's going on, to determine what should be done, and to coordinate action (Schulman, 1993: 43). They allow influence and authority to migrate toward expertise and experience no matter where it lies within the hierarchy (Bigley \& Roberts, 2001). The result is that they are better at applying the organizational knowledge necessary to mitigate problems.

Improvise. Unexpected events rarely conform to preexisting solution sets. Thus, when faced with a crisis, people in HROs avoid mindlessly using existing policies and procedures (i.e., working to rule) unless they are certain of their applicability (Weick, 1990; Weick \& Sutcliffe, 2001). Instead, they improvise. They accomplish novel tasks through the creative use of available resources to reduce the time between discovery and execution to close to zero. They quickly and easily change performance strategies and modify or switch tactics (Bigley \& Roberts, 2001). In short, people in HROs regularly develop innovative solutions to puzzling and complex problems on-the-fly.

\section{Generativeness}

Finally, HROs strive to become more diligent, more facile, and more fluid over time. They are, in effect, learning organizations. Since trial-and error learning is out of the question, HROs work to squeeze as much new knowledge as possible out of their successes and failures as well as the experiences of others (Haunschild \& Sullivan, 2002). Organizational learning is stifled when people become overconfident or complacent (Starbuck \& Milliken, 1988). Thus, HROs seek to create a workforce that is collectively curious and open to new insights, one comprised of people that are always learning and educating. 
Learn. People in HROs continuously strive to go deeper and wider in their skills and understandings. They "over learn" critical tasks to offset the tendency for those skills to unravel under pressure (Weick, 1990: 590). They pursue the attainment of proficiency in multiple competency domains. People in HROs are also tenacious about learning from the past. They view every incident, no matter how small, as an opportunity to learn something valuable for the future. They dig deeply to locate the root causes of past problems and are suspicious of simple, surface level explanations. They realize that opportunity for learning from experience diminishes rapidly as time elapses, so they conduct formal or informal incident assessments immediately (Weick \& Sutcliffe, 2001).

Educate. People in HROs also take responsibility for each other's learning by openly sharing information and knowledge with colleagues both inside and across departmental boundaries. This knowledge sharing often occurs on the spot: when people in HROs have an insight, they stop what they are doing and spontaneously convene people to share the discovery (Schulman, 1993).

Taken together, the eight ROEBs discussed above comprise a highly interdependent set. They are complementary in that when people exhibit more (less) of any one of them, they increase (decrease) the returns of demonstrating the others. For example, "when people bring new variables under their control and enlarge their ability to act on them, they also enlarge the range of issues they can notice... Conversely, if people are blocked from acting on hazards, it is not long before their 'useless' observations of those hazards are also ignored or denied, and errors accumulate unnoticed" (Weick, et. al., 1999: 90). Further, the relationship between ROEBs and organizational reliability should be clear. ROEBs, to a large extent, comprise an organization's capacity (a) to anticipate or detect surprises early without compromising routine operations (i.e., ascertain and communicate), (b) to switch from stable and routine activity to flexible and novel action and then back again quickly (i.e., initiate and deploy), (c) to operate 
effectively in chaotic situations (i.e., coact and improvise), and (d) to get increasingly diligent, facile, and fluid over time (i.e., learn and educate). Thus, it can be postulated that:

Proposition 1: ROEBs will be positively related to organizational reliability. The better a reliability seeking organization's employees are at ascertaining, communicating, initiating, deploying, coacting, improvising, learning, and educating, the more reliable that organization's performance.

\section{Trying Conditions}

Theory and research on reliability seeking organizations generally assumes that the organizations in question operate under "trying conditions" (Weick et al., 1999). That is, they manage highly complex and interdependent systems that are subject to substantial external volatility. Consider, for example, the case of nuclear aircraft carriers as described in Roberts (1990) and Weick and Roberts (1993). These organizations (a) operate between two and eight nuclear reactors (which generate enough power to meet the needs of a city the size of Minneapolis), monitor over a billion electronic components, and use technical manuals that, if stacked, would be as high as the Washington Monument (i.e., their systems are complex); (b) require twenty real-time communication devices between the ship's control tower and the rest of the units to coordinate the simultaneous taking off and landing of aircraft (i.e., their tasks and routines are interdependent); and (c) experience dramatic changes in the weather as well as the (potential) unexpected actions of the "enemy" (i.e., their external environments are volatile).

Trying conditions are important contextual factors because collectively they trigger and magnify three types of organizational failure that are difficult to prevent, anticipate, and fix. First, trying conditions increase the likelihood of a so-called "normal" disasters in which single problems lead to chain reactions that reverberate through the system and trigger a cascade of malfunctions and breakdowns (Perrow, 1984). Second, trying conditions are associated with failures of foresight in which organizations are blindsided by unexpected (and often 
inconceivable) changes in their external environments (Weick, 1993). Finally, trying conditions lead to quantity failures in which normally mundane events overaccumulate to such an extent that they collectively overwhelm the capacity of the system and lead to a rapid deterioration of performance and, eventually, catastrophe (Rudolph \& Repenning, 2002). Of course, attaining reliability under trying conditions is made even more difficult when one realizes that crises rarely limit themselves to single failure type (Rudolph \& Repenning, 2002: 27).

Organizations' relative susceptibility to these types of failures, in turn, has important implications for the value of ROEBs. As noted earlier, prior HRO theory and research suggest that when the potential for catastrophic failure is high (i.e., organizations operate under trying conditions), then organizational reliability is enhanced when people are diligent, facile, fluid, and generative. But, it stands to reason that as work conditions become less trying, and thus the risks of failure recede, so too should the value of ROEBs. Reliability seeking organizations that execute simple and straightforward tasks under stable conditions are capable of designing more or less foolproof processes and planning for virtually all contingencies in advance. As a result, the effectiveness of such systems is less likely to depend on peoples' capacities to identify a wide range of potential threats (ascertain), to manage hand-offs and interdependence (communicate), to take appropriate action to mitigate and rectify unexpected events (initiate), to switch tasks and role quickly and easily (deploy), to spontaneously engage unfamiliar colleagues (coact), to perform non-routine actions on-the-fly (improvise), to have deep and wide understanding of the system (learn), and to share knowledge both within and across units (educate).

In sum, then, the HRO literature argues that context moderates the relationship between system design and performance. When considered from an employee behavior perspective, this means that organizations operating under trying conditions should require more and/or greater quality ROEBs than do organization operating systems in predictable and stable settings. Indeed, it is possible that organizations operating under less trying conditions achieve 
high levels of reliability through a modified, or even a completely different, set of employee behaviors. In either case, though, it can be suggested that:

Proposition 2: Trying conditions moderate the relationship between ROEBs and organizational reliability. The more complex, more interdependent, and more volatile the operating conditions, the stronger the relationship between ROEBS and organizational reliability.

\section{Reliability-Enhancing Human Resource Strategy}

Now that we have identified a set of reliability-oriented employee behaviors and delineated the contextual conditions under which they are likely to be most effective, the next question is, what human resource strategy best brings them about?

HRO theory and research is relatively silent here since little attention has been specifically devoted to human resource management issues. As noted earlier, though, HRO scholars do point to many organizational infrastructure features and employee mindset shaping activities that likely influence performance through employee behaviors. Recall, for example, that Weick (1988) suggested that carrying some human resource slack or redundancy positively affects people's willingness and ability to ascertain and improvise. Further, the closer one gets to HRO practice, the more human resource management activities are discussed as key mechanisms that organizations can use to foster higher reliability. Weick and Sutcliffe (2001:57), for instance, suggest that HROs "put premium on recruiting and selection processes". Roberts and Bea (2001a: 72) note that "HROs spend disproportionately more money than other organizations training people".

From a SHRM perspective, the discussion of human resource strategy begins with the HPHRS. But, defining and specifying the HPHRS is not easy (Becker \& Gerhart, 1996; Dyer \& Reeves, 1995). This is, in part, because the HPHRS refers to two distinct, yet blurred, streams 
of human resource strategy research: high performance work systems (HPWSs) and "best practices" (see Table 1).

\section{Table 1}

High Performance Human Resource Strategy

\begin{tabular}{|l|l|l|l|}
\hline & \multicolumn{1}{|c|}{ HPWS } & \multicolumn{1}{c|}{$\begin{array}{c}\text { HPHRS } \\
\text { "Best Practices" }\end{array}$} & \multicolumn{1}{c|}{ REHRS } \\
\hline Focus & Organizing system & HR management & Organizing System \\
\hline Emphasis & HR principles & HR activities & HR principle \\
\hline Specificity & High & Low & High \\
\hline
\end{tabular}

The HPWS stream, at its name implies, focuses on organizing systems: in particular, production systems (Appelbaum, Bailey, Berg, \& Kalleberg, 2000). Rooted in socio-technical systems theory, HPWS research digs deeply into interrelationships among people, process, and technology. Early work, for instance, emphasizes the "organizational logic" in favor of matching HPWSs to flexible production systems and control-oriented human resource strategies to classic mass production approaches (MacDuffie, 1995). Since the focus is on the organizing system, the HPWS stream also tends to emphasize human resource strategy principles -general themes that theoretically guide the selection and grouping of human resource activities - rather than just the human resource activities themselves. For example, a HPWS has come to refer to (a) increasing workforce skill levels, (b) providing employees discretion and opportunity to use their skills in collaboration with other workers, and (c) offering an incentive structure that enhances motivation and commitment (Batt, 2002: 587). It's not that HPWS scholars are not interested human resource activities though. Rather, HPWS research tends to assess each principle with human resource activities that are highly specific to the work system. For example, Batt's (2002) examination of call centers included items capturing the extent to which employees can control the pace with which they can answer phones, are allowed to 
handle nonroutine service requests themselves, and are subject to extensive electronic monitoring. Thus, HPWS research can be characterized as focusing on the work system performance, emphasizing human resource management principles, and greatly specifying human resource activities.

"Best practice" research, on the other hand, refers to large scale cross industry studies that relate one or more human resource activities on the one hand to one or more measures of organizational effectiveness on the other hand. This stream's roots can be traced to functional human resource activity studies that extend individual level findings (e.g., the relationship between compensation practices and employee effort and persistence) to the firm level (e.g., the relationship between compensation practices and firm performance). Here the focus is on human resource management, not organizing systems. Further, the emphasis is on human resource activities rather than principles in that researchers usually begin with a set of human resource activities and then aggregate up to principles (usually through factor analysis) rather than the other way around. Further, because the focus in at the firm level, "best practice" research tends to be more general in its treatment of human resource activities. (A question about the percentage of work performance of the typical employee that is electronically monitored, for example, is clearly relevant to work systems than to a randomly selected cross section of firms.) Thus, "best practice" research involves focusing on human resource management, emphasizing HR activities, and doing so at a fairly general level.

The HPWS and "best practices" streams have merged over time into what can be referred to as a HPHRS. This integration is the result of at least two factors. First, HPWS research has generally found that enhancing workforce competence, expanding employee discretion and participation, and bolstering employee commitment and motivation result in greater performance regardless of work system employed (Appelbaum et. al., 2000; Ichniowski, Kochan, Levine, Olson, \& Strauss, 1996). Thus, in a practical sense, the human resource activities that comprise these three principles are "best practices" across the sample of firms 
studied. Second, the human resource activities that comprise a HPWS are very similar to those found to be crucial to firm performance by researchers in the "best practice" stream. Both streams, for example, would agree that performance is likely enhanced by employment security, selective hiring of new personnel, self-managed teams and decentralization of decision making, comparatively high compensation contingent on organizational performance, extensive training, reduced status distinctions across organizational levels, and the sharing of financial and performance information throughout the organization (Pfeffer, 1998). Clearly, then, unless there is reason to believe otherwise, one would expect these best practices to be positively related to HRO performance. But, as the preceding discussion suggests, identifying a human resource strategy for HROs (even a HPHRS) requires also making some choices about focus, emphasis, and specificity.

Like the HPWS stream, our focus here is on the organizing systems that HROs use to foster reliability. After all, HRO theory and research emphasizes the structures, processes, and technologies that HROs use to avoid or permanently delay failures. HRO scholars also stress the fact that the systems employed by reliability seeking organizations operating under trying conditions are markedly different from those used by traditional efficiency seeking organizations that operate in more stable and predictable environments (Weick et. al., 1999; Weick \& Roberts, 1993; Weick \& Sutcliffe, 2001). If this is true, then it naturally follows that the performance enhancing human resource strategies that HROs use should be (somewhat to quite) different from those identified by HPWS literature. One important issue, though, is how to handle these infrastructure features. The HPWS literature, it will be recalled, tends to separate human resource strategy from organizational infrastructure and then looks to see whether firms that match their human resource strategies to their organizational infrastructures perform better than do those that do not. A behavioral approach, though, favors beginning with a set of critical employee behaviors (i.e., ROEBs) and then moving back to identify broad principles comprised 
of both infrastructure features and human resource management activities likely to bring them about.

Consistent with a systems focus, we also elect to emphasize human resource strategy principles over human resource activities. As systems level constructs, principles are more logically related to systems level outcomes (e.g., it makes more sense that "expanding employee discretion and participation" would be related to high reliability than would "the percentage of employees that participate in off-line problem solving groups"). As a result, SHRM scholars increasingly suggest that human resource strategy be conceptualized at the principle rather than the activity level of analysis (Becker \& Gerhart, 1996; Dyer \& Shafer, 1999, 2003; Wright, 1998). Further, principles are more condusive to the assessment of vertical and horizontal fit than activities are since they allow for the determination (conceptually or empirically) of whether (a) the identified principles are individually necessary and collectively sufficient to engender the outcome of interest (ROEBs in this case) and (b) the various human resource activities that comprise the principles are mutually reinforcing, respectively.

Finally, our unique context (HROs) and particular outcome emphasis (ROEBs) allows us to be quite specific with respect to infrastructure features and human resource activities. Wright (1998) suggests that SHRM scholars need to pay close attention to the differences between human resource principles (e.g., pay for performance), practices (e.g., merit pay, bonuses, piece rates), particulars (e.g., competencies versus supervisor rankings as the basis for determining merit pay), and products (e.g., the exact performance that a supervisor rates employees on to determine their merit pay). Wright (1998) also suggests that the more researchers able to get to the product level of assessment, the better their chances are for finding fit.

In the remainder of this section, we leverage prior HRO and SHRM thinking to identify a system-driven, principle-based REHRS comprised of specific organizational infrastructure 
features and human resource management activities. Then, we conceptually assess the REHRS principles on the basis of their collective capacity to support vertical and horizontal fit.

\section{A Six Principle REHRS}

Principle 1: Embed an obsession for reliability. HROs are hazardous and dangerous places where mistakes and surprises have catastrophic consequences for people, society, and the environment. Despite well-known risks, however, many disastrous organizational failures can be traced back to individual decisions to compromise on reliability in favor of other (usually noble and important) objectives (Perrow, 1984; Shrivasta, 1987; Weick, 1988, 1990). Thus, HROs do everything they can to avoid even the smallest lapses by embedding an obsession for reliability deep into the bowels of the organization (Weick et. al., 1999).

To embed an obsession for reliability, HROs entrench reliability objectives into organizational missions, values, and performance metrics (Weick et. al., 1999). They insure that virtually every piece of formal communication going to employees reinforces some aspect of reliability (Roberts \& Bea, 2001a). They reward and celebrate reliability way over and way above productivity or efficiency (Roberts \& Bea, 2001b). Finally, HROs select and promote people on the basis of their adherence to organizational mission and values (i.e., power hungry individualists need not apply) (Weick \& Sutcliffe, 2001).

Principle 2: Promote contextual clarity. Understanding that reliability is the uncontested organizational priority is not enough. According to Weick and Sutcliffe (2001: 63), another "key to effective performance lies in maintaining situational awareness, the big picture of current operations, or in the language of aircraft carriers, having the bubble". HROs thus seek to promote contextual clarity. That is, they work hard to ensure that employees can effectively integrate their local knowledge with the overall situational and operational status of the system and then extend their analysis forward in time to envision potential future implications. 
To promote contextual clarity, HROs provide employees with lots of real-time operating information (e.g., situational assessments with continual updates) and ensure that they know what to do with it (Eisenhardt, 1993). They develop early warning systems; these systems are often technology-driven but they also can take the form of guidelines or heuristics (Roberts, 1990). They employ communication protocols to facilitate the dissemination of information between individuals and across units (Weick et. al., 1999). Finally, they train employees continuously in the physical and dynamic properties of the technical system to ensure that employees can effectively analyze both the upstream and downstream consequences of their actions (Weick \& Sutcliffe, 2001: 57).

Principle 3: Foster reconfigurability. Systems fail when they lack requisite variety; that is, when the scope and scale of unexpected events exceeds their range of potential solutions and repairs. HROs, of course, operate in settings ripe for "normal" disasters, failures of foresight, and quantity-induced breakdowns; contexts where the inconceivable is not only possible but also likely. To achieve resiliency in the face of such challenging demands, HROs foster reconfigurability. They strive to develop people and infrastructures flexible enough not only to routinely handle a wide-range of unexpected events but also to effectively manage all remaining surprises through successful ad hoc action.

To foster reconfigurability, HROs design contingency plans in advance and then provide employees lots of training and practice in using them (Bigley \& Roberts, 2001). They develop guidelines that specify when and how people should shut down the system, deploy additional resources, and/or trigger the alteration of structures (Weick \& Roberts, 1993). They underspecify and overstaff critical roles so that people have the flexibility and freedom necessary to quickly and easily act when it is necessary to do so (Weick et. al., 1999). Finally, they push decision-making authority and the discretion to act down to the lowest possible levels (Weick, 1990). 
Principle 4: Instill accountability. HROs also work hard to ensure that irrespective of whether employees are executing routine tasks or responding to an emergency, they are always operating within the boundaries (and the best interests) of the system (Vaughan, 1999). They consider even one case of "freelancing" to be one too many because they realize that such behaviors often create more problems than they solve (Bigley \& Roberts, 2001). HROs thus instill accountability by regularly asking employees to explain their conduct both formally and informally.

To instill accountability throughout the system, HROs embed redundancy in the form of duplication and backups (Roberts, 1990). They create clear lines of responsibility to ensure that, even though people are always watching one another's backs, employees know where the "buck stops" (Roberts, Stout \& Halpern, 1994). They practice zero-tolerance for even smallscale actions that compromise reliability or impair collective action. Finally, HROs implement frequent and thorough performance management systems (Weick \& Sutcliffe, 2001).

Principle 5: Facilitate development. The road to disaster is often paved by complacency and obsolescence. Thus, HROs strive to facilitate the continual development of their systems and people. The goal is to ensure that the organization is constantly forcing, and then helping, people to know what they don't know (Roberts \& Bea, 2001a).

To facilitate development, HROs regularly assess core processes and procedures and go to great lengths to avoid structural decoupling in which the procedures on the books look nothing like actual practice (Hynes \& Prasad, 1997). They are vigilant about using "incident review" processes where breakdowns (both small and large) and near misses are openly and honestly examined and, when necessary, rectified (Carroll, 1995, 1998; Haunschild \& Sullivan, 2002; Schulman, 1993). They provide employees with lots of opportunities for new training, retraining, and cross training and they do so in forms that are friendly and easy to use (Weick \& Sutcliffe, 2001). Finally, they create communities of practice to allow people to develop in-depth 
knowledge of particular topics and to share that knowledge with others across unit and organizational boundaries.

Principle 6: Encourage security. HROs are clearly not for everyone. They employ people with highly specialized skills and then ask them to be diligent, facile, fluid, and generative under challenging and stressful circumstances. On the other hand, employee turnover and hiring mistakes can lead to serious system disruption and even instability. Thus, HROs work hard to encourage employment and psychological security.

To encourage security, HROs formally and informally reward people for raising concerns and pointing out errors (Weick et. al., 1999). They never punish, belittle, or make scapegoats out of people when their actions are consistent with organizational goals. They minimize voluntary turnover by (a) carefully selecting employees and offering candidates realistic job previews and (b) providing better than average pay. They avoid layoffs at all costs. Finally, HROs rarely use contract or outsourced employees because their systems are too complicated, integrated, and volatile to leave reliability-oriented workforce behaviors under the influence of any other organization.

\section{Conceptually Assessing Fit}

Are these six principles likely to foster ROEBs in a mutually reinforcing way? Clearly, this is a crucial question. But, before we take it up, it is important to point out a few caveats. First, testing for vertical fit is ultimately an empirical task. Second, demonstrating that a REHRS synergistically drives ROEBs is a meaningless exercise unless a valid relationship exists between the ROEBs and organizational reliability. Finally, this analysis is meant only to suggest that the underlying reasoning behind our six REHRS principle choices is sound, after all they were developed with vertical and horizontal fit in mind.

Vertical fit. A preliminary case for vertical fit can be made by showing that each REHRS principle is necessary, and that collectively they are sufficient, to foster ROEBs. That 
is, by logically demonstrating that each ROEB is supported by at least one REHRS principle and that each REHRS principle addresses at least one ROEB. As Table 1 shows, the six REHRS principles collectively meet this test: each ROEB is supported by a minimum of four REHRS principles and each REHRS principle addresses at least four of the ROEBs. Collectively these REHRS principles promote focus (embed an obsession for reliability), line of sight (promote contextual clarity), discretion (foster reconfigurability), discipline (instill accountability), competence (facilitate development), and safety (encourage security). Thus, the REHRS principles identified here are likely to engender employees that ascertain, communicate, initiate, deploy, coact, improvise, learn, and educate.

Table 2

\section{Assessing Vertical Fit}

\begin{tabular}{|c|c|c|c|c|}
\hline $\begin{array}{l}\text { Organizing } \\
\text { Principle }\end{array}$ & $\begin{array}{l}\text { Diligent } \\
\text { Ascertain and } \\
\text { communicate }\end{array}$ & Initiate and deploy & Coact and improvise & $\begin{array}{c}\text { Generative } \\
\text { Learn and Educate }\end{array}$ \\
\hline $\begin{array}{l}\text { Embed an } \\
\text { obsession for } \\
\text { reliability }\end{array}$ & $\begin{array}{l}\text { Reinforces the } \\
\text { need for } \\
\text { diligence }\end{array}$ & $\begin{array}{l}\text { Reinforces the need to } \\
\text { take rapid and } \\
\text { appropriate action }\end{array}$ & $\begin{array}{l}\text { Reinforces the need for } \\
\text { effective joint effort }\end{array}$ & $\begin{array}{l}\text { Reinforces the need } \\
\text { to nurture collective } \\
\text { intelligence }\end{array}$ \\
\hline $\begin{array}{l}\text { Promote } \\
\text { contextual } \\
\text { clarity }\end{array}$ & $\begin{array}{l}\text { Provides the } \\
\text { understanding } \\
\text { necessary to } \\
\text { anticipate and } \\
\text { detect } \\
\text { surprises }\end{array}$ & $\begin{array}{l}\text { Provides understanding } \\
\text { of how and when to take } \\
\text { action and how such } \\
\text { decisions contribute to } \\
\text { reliability }\end{array}$ & $\begin{array}{l}\text { Guides joint efforts and } \\
\text { provides understanding } \\
\text { of how collective action } \\
\text { fosters reliability }\end{array}$ & $\begin{array}{l}\text { Provides insights into } \\
\text { areas for future } \\
\text { development }\end{array}$ \\
\hline $\begin{array}{l}\text { Foster } \\
\text { reconfigurability }\end{array}$ & & $\begin{array}{l}\text { Provides the resources } \\
\text { and skills necessary to } \\
\text { take action }\end{array}$ & $\begin{array}{l}\text { Nurtures these } \\
\text { behaviors and facilitates } \\
\text { the movement of } \\
\text { resources to where they } \\
\text { can best be employed }\end{array}$ & \\
\hline $\begin{array}{l}\text { Instill } \\
\text { accountability }\end{array}$ & $\begin{array}{l}\text { Reinforces the } \\
\text { need for } \\
\text { diligence }\end{array}$ & & $\begin{array}{l}\text { Shapes and directs joint } \\
\text { action }\end{array}$ & \\
\hline $\begin{array}{l}\text { Facilitate } \\
\text { development }\end{array}$ & $\begin{array}{l}\text { Provides } \\
\text { essential } \\
\text { competencies }\end{array}$ & $\begin{array}{l}\text { Provides essential } \\
\text { competencies }\end{array}$ & $\begin{array}{l}\text { Provides multiple } \\
\text { competencies }\end{array}$ & $\begin{array}{l}\text { Provides mechanisms } \\
\text { for individual and } \\
\text { collective learning }\end{array}$ \\
\hline $\begin{array}{l}\text { Encourage } \\
\text { security }\end{array}$ & $\begin{array}{l}\text { Reinforces } \\
\text { open and } \\
\text { honest } \\
\text { communication }\end{array}$ & $\begin{array}{l}\text { Provides collective } \\
\text { experience necessary to } \\
\text { know when and how to } \\
\text { take action }\end{array}$ & $\begin{array}{l}\text { Provides a sense of } \\
\text { collegiality and } \\
\text { familiarity }\end{array}$ & $\begin{array}{l}\text { Promotes real } \\
\text { dialogue about areas } \\
\text { for individual and } \\
\text { collective growth }\end{array}$ \\
\hline
\end{tabular}


Horizontal fit. A preliminary case for horizontal fit, in turn, can be made by showing that each REHRS principle is supported by multiple policies, programs, and practices and that each policy, program, and practice addresses multiple REHRS principles. As Table 2 suggests, the 26 REHRS policies, programs, and practices meet this twin test. Each REHRS principle is comprised of at least four policies, programs and practices and each policy, program, and practice addresses at least two REHRS principles. One can also estimate complementarity among REHRS policies, programs, and principles by judging whether doing more (or less) of any one of them would increase (decrease) the returns of doing the others. In both cases, it appears as though the policies, programs, and practices that comprise a REHRS are mutually reinforcing and constitute a synergistic organizing system. 
Table 3

\section{Assessing Horizontal Fit}

\begin{tabular}{|c|c|c|c|c|c|c|}
\hline REHRS-related policies, programs, and practices & $\begin{array}{l}\text { Embed an obsession } \\
\text { for reliability }\end{array}$ & $\begin{array}{c}\text { Promote } \\
\text { contextual clarity }\end{array}$ & $\begin{array}{c}\text { Foster } \\
\text { reconfigurability }\end{array}$ & $\begin{array}{c}\text { Instill } \\
\text { accountability }\end{array}$ & $\begin{array}{c}\text { Facilitate } \\
\text { development }\end{array}$ & $\begin{array}{l}\text { Encourage } \\
\text { security }\end{array}$ \\
\hline $\begin{array}{l}\text { Entrench reliability into organizational mission, values, and } \\
\text { performance metrics }\end{array}$ & + & + & + & + & + & \\
\hline $\begin{array}{l}\text { Insure that virtually all communication reinforces some aspect } \\
\text { of reliability }\end{array}$ & + & + & + & + & + & \\
\hline $\begin{array}{l}\text { Reward and celebrate reliability way over and way above } \\
\text { productivity or efficiency }\end{array}$ & + & & & & + & + \\
\hline $\begin{array}{l}\text { Select and promote people on the basis of their adherence to } \\
\text { organizational mission and values }\end{array}$ & + & & & + & + & + \\
\hline $\begin{array}{l}\text { Provide employees with lots of real-time operating } \\
\text { information }\end{array}$ & + & + & + & & & \\
\hline Develop early warning systems & + & + & + & & & \\
\hline Employ communication protocols & + & + & + & + & & + \\
\hline $\begin{array}{l}\text { Train employees continuously in the physical and dynamic } \\
\text { properties of the system }\end{array}$ & + & + & + & + & + & \\
\hline Design (often alternate) contingency structures & + & & + & + & & \\
\hline $\begin{array}{l}\text { Develop guidelines that specify when and how people should } \\
\text { shut down the system, deploy additional resources, } \\
\text { and/or trigger the alteration of structures }\end{array}$ & & & + & + & & + \\
\hline Underspecify and overstaff critical roles & + & + & + & & + & \\
\hline $\begin{array}{l}\text { Push decision-making authority down to the lowest possible } \\
\text { levels }\end{array}$ & & + & + & + & + & + \\
\hline Embed redundancy in the form of duplication and backups. & + & + & + & + & & + \\
\hline Create clear lines of responsibility & + & + & + & + & & \\
\hline $\begin{array}{l}\text { Practice zero-tolerance for actions that compromise reliability } \\
\text { or impair collective action }\end{array}$ & + & & & + & & + \\
\hline $\begin{array}{l}\text { Implement a frequent and thorough performance } \\
\text { management system }\end{array}$ & + & + & & + & + & \\
\hline Regularly assess core processes and procedures & + & & + & & + & \\
\hline Vigilant about using "incident review" processes & + & & & + & + & + \\
\hline $\begin{array}{l}\text { Provide employees with lots of opportunities for new training, } \\
\text { retraining, and cross training }\end{array}$ & & + & + & & + & \\
\hline Create communities of practice & + & + & & & + & \\
\hline Reward people for raising concerns and pointing out errors. & + & + & + & + & & + \\
\hline Select employees carefully and thoroughly & + & & & & & + \\
\hline Offer candidates realistic job previews & & + & & & & + \\
\hline Provide better than average pay & & & & & + & + \\
\hline Avoid layoffs at all costs & & & & & + & + \\
\hline Eschew the use of contract or outsourced employees & + & & + & + & + & + \\
\hline
\end{tabular}


In sum, then, after considering HPHRS research, we used prior HRO and SHRM thinking to identify a system-driven, principle-based REHRS comprised of specific organizational infrastructure features and human resource management activities. Then, we conceptually assessed the REHRS principles on the basis of their collective capacity to support vertical and horizontal fit. Based on these analyses, it can be argued that:

Proposition 3: The REHRS will be positively related to reliability-oriented employee behaviors. The more an organization forges an obsession for reliability, promotes contextual clarity, fosters reconfigurability, instills accountability, facilitates development, and encourages security, the more diligent, facile, fluid, and generative its employees.

According to the behavioral approach, human resource strategy (and thus organizational infrastructure and human resource management activities) does not play a direct role in anticipating or detecting surprises, switching from stable and routine activity to flexible and novel action, operating effectively in chaotic situations, and continuously improving over time -- the core capabilities associated with organizational reliability. Instead, it facilitates employee's taking appropriate action to accomplish these critical tasks. Thus, ROEBs should mediate the effects of a REHRS on organizational reliability.

Proposition 4: Reliability-oriented employee behavior mediates between REHRS and organizational reliability.

\section{Conclusion}

The SHRM literature presently emphasizes a single human resource strategy -- the HPHRS. This is not unreasonable given the number of studies suggesting that firms that selectively hire new personnel, offer comparatively high compensation contingent on organizational performance, provide extensive training, and so forth tend to outperform firms that do not. But, before it can be concluded that a general HPHRS is preferable regardless of 
organizational goals, contexts, or organizing systems, it is necessary to delve deeper into the so-called "black box" that exists between human resource activities on the one hand, and organizational effectiveness on the other (Becker \& Gerhart, 1996). SHRM theory is based, to a large extent, on the assumption that certain organizational goals require certain employee behaviors and that certain human resource strategies produce certain employee behaviors (Cappelli \& Singh, 1992; Schuler \& Jackson, 1987). Yet, the literature lacks detailed examples of such behavioral approaches. In this article, we begin to address this gap by presenting a behavioral SHRM model of HRO performance.

How do people contribute to organizational reliability? Prior HRO theory and research suggests that reliability is fostered to the extent that people ascertain and communicate to anticipate and detect a large number and variety of problems and surprises; initiate and deploy to execute substitute structures and processes that facilitate the bringing of problems under control; coact and improvise to face down emergencies in new and novel ways; and learn and educate to continually become more diligent, more facile, and more fluid over time. These eight ROEBs are clearly organizational goal specific. Thus, they should be more valuable for organizations focused on reliability than for organizations pursuing other performance outcomes. Further, they should explain variance in reliability that general behaviors such as pro-social, citizenship, and turnover do not.

How context specific are ROEBs? The HRO literature focuses on organizations that operate under trying conditions, i.e., those that manage complex and interdependent systems subject to substantial external volatility. Thus, the ROEBs we extract from HRO theory and research are highly context specific. A common theme in the HRO literature is that the systems (and, thus, presumably employee contributions) that enhance reliability in relatively simple, straightforward, and stable environments are unlikely to be effective rapidly changing and unpredictable ones (Weick et. al., 1999; Weick \& Roberts, 1993; Weick \& Sutcliffe, 2001). In stable environments, reliability is achieved through foolproof and resilient structures, 
technologies, and processes. But, such systems are failure prone in trying circumstances. Instead, trying conditions require systems capable of continuously remaining one step ahead of actual or potential problems, errors, and surprises; systems that are continually and concurrently diligent, facile, fluid, and generative. Of course this type of organizational ambidexterity is exceedingly difficult to achieve (Tushman \& O'Reilly, 1996: Wright \& Snell, 1998). Thus, it should not come as a surprise that scholars increasingly suggest that HROs are a good place in which to study new organizational forms (Bigley \& Roberts, 2001; Weick et. al., 1999) or that the behaviors identified here closely resemble those thought to enhance organizational agility (Dyer \& Shafer, 1999, 2003). In any case, our analysis suggests that desirable behaviors are likely to be both organizational goal and context specific and that SHRM theory and research would benefit more from deeper and richer explorations into the settings and circumstances in which certain employee behaviors enhance certain types of organizational performance.

What human resource strategy facilitates the manifestation of ROEBS? Consistent with the HPWS stream of HPHRS theory and research, we chose to develop a systems-focused, principle-based REHRS comprised of specific organizational infrastructure features and human resource management activities. Six key REHRS principles were identified: embed an obsession for reliability, promote contextual clarity, foster reconfigurability, instill accountability, facilitate development, and encourage security. Conceptual analyses suggest that these six principles are individually necessary and collectively sufficient to engender ROEBs (implying vertical fit) and mutually reinforcing (suggesting horizontal fit) respectively. Thus, we conclude that organizations that demonstrate these principles (through the infrastructure elements they employ and the human resource activities they utilize) are be more likely to engender ROEBs in their workforces than are organizations that do not.

Is the REHRS different from the HPHRS? In one sense, the answer to this question is not really. The REHRS we present here is consistent with "best practice" HPHRS findings that 
providing employment security, selectively hiring new personnel, decentralizing decision making, providing extensive training, and sharing financial and performance information throughout the organization, enhances organizational performance (Pfeffer, 1998). That said, though, the REHRS principles (and related infrastructure features and human resource activities) we present are highly HRO specific. As a result, the REHRS should predict ROEBS better than a generic HPHRS would. (The converse, of course, is also true: the REHRS is unlikely to do a good job predicting other organizational goal- and/or context-oriented employee behaviors.) Thus, future research might fruitfully explore other ways in which the HPHRS can be tailored to other organizational goal- and/or context-specific employee behaviors.

In another sense, though, the REHRS and HPHRS are quite different. The REHRS is conceptually most similar to the HPWS stream of HPHRS theory and research in that both focus on a particular organizing systems, emphasize principles, and identify highly specific human resource activities. But, while the HPWS was designed with flexible manufacturing systems in mind, the REHRS focuses on organizing systems capable of virtually problem free performance under the most trying of circumstances. If these two organizing systems differ substantially (as HRO scholars suggest), then it clearly follows that their performance-enhancing human resources strategies should as well. Future research, then, should continue working to uncover the human resource strategies that organizations use to develop and sustain new forms of organizing. 


\section{References}

Appelbaum, E., Bailey, T., Berg, P., \& Kalleberg, A. 2000. Manufacturing advantage. Ithaca, NY: ILR Press.

Arthur, J.B. 1992. The link between business strategy and industrial relations systems in American steel mini-mills. Industrial and Labor Relations Review, 45: 488-506.

Batt, R. 2002. Managing customer services: Human resource practices, quit rates, and sales growth. Academy of Management Journal, 45: 587-597.

Becker, B.E., \& Gerhart, B. 1996. The impact of human resource management on organizational performance: Progress and prospects. Academy of Management Journal, 39: 779-801.

Becker, B.E., \& Huselid, M.A. 1998. High performance work systems and firm performance: A synthesis of research and managerial implications. In Ferris et. al. (Eds.), Research in Personnel and Human Resource Management. Stamford, CT: JAI Press.

Bierly, P.E., \& Spender, J.-C. 1995. Culture and high reliability organizations: The case of the nuclear submarine. Journal of Management, 21: 639-656.

Bigley, G.A., \& Roberts, K.H. 2001. The incident command system: High reliability organizing for complex and volatile task environments. Academy of Management Journal, 44: 12811299.

Bourrier, M. 1996. Organizing maintenance work at two nuclear power plants. Journal of Contingencies and Crisis Management, 4: 104-112.

Boxall, P., \& Purcell, J. 2000. Strategic human resource management: Where have we come from and where are we going? International Journal of Management Reviews, 2: 183203.

Cappelli, P., \& Singh, H. 1992. Integrating strategic human resources and strategic management. In D. Lewin, Mitchell, \& P. Sherer (eds.), Research Frontiers in Industrial Relations and Human Resources. Madison, WI: Industrial Relations Research Association.

Carroll, J.S. 1998. Organizational learning activities in high-hazard industries: The logic of selfanalysis. Journal of Management Studies, 35: 699-717.

Carroll, J.S. 1995. Incident reviews in high hazard industries: Sense making and learning under ambiguity and accountability. Industrial and Environmental Crisis Quarterly, 9: 175-197.

Creed, W.E.D., Stout, S.K., \& Roberts, K.H. 1993. Organizational effectiveness as a theoretical foundation for research on reliability-enhancing organizations. In K.H. Roberts (Ed.), New challenges to understanding organizations: 55-74. New York: Macmillan.

Delery, J., \& Doty, H. 1996. Modes of theorizing in strategic human resource management: Tests of universalistic, contingency, and configurational performance. Academy of Management Journal, 39: 812-835.

Delery, J., \& Shaw, J. 2001. The strategic management of people in work organizations: Review, synthesis, and extension. In G. Ferris (Ed.), Research in Personnel and Human Resources Management, Vol. 20. Oxford, UK: Elsevier Science.

Dyer, L., \& Holder, G.W. 1988. A strategic perspective of HRM. In L. Dyer \& G.W. Holder (Eds.), Human Resource Management: Evolving Roles and Responsibilities. Washington, D.C.: Bureau of National Affairs.

Dyer, L., \& Reeves, T. 1995. Human resource strategies and firm performance: What do we know and where do we need to go? The International Journal of Human Resource Management, 6: 656-670.

Dyer, L., \& Shafer, R.A. 1999. From human resource strategy to organizational effectiveness: Lessons from research on agile organizations. In P. Wright, L. Dyer, J. Budreau, \& G. Milkovich (Eds.): Research in Personnel and Human Resources Management 
(Supplement 4: Strategic Human Resource Management in the $21^{\text {st }}$ Century). Stamford, CT: JAI Press.

Dyer, L., \& Shafer, R.A. 2003. Dynamic organizations: Achieving marketplace and organizational agility with people. In R. Peterson \& E. Mannix (Eds.), Understanding the Dynamic Organization. Mahwah, NJ: Lawrence Earlbaum Associates.

Edmondson, A.C. 1996. Learning from mistakes is easier said than done: Group and organizational influences on the detection and correction of human error. Journal of Applied Behavioral Science, 32: 5-28.

Eisenhardt, K.M. 1993. High reliability organizations meet high velocity environments: Common dilemmas in nuclear power plants. In K.H. Roberts (Ed.), New challenges to understanding organizations: 117-136. New York: Macmillan.

Hannan, M.T., \& Freeman, J. 1984. Structural inertia and organizational change. American Sociological Review, 49: 149-164.

Haunschild, P.R., \& Sullivan, B.N. 2002. Learning from complexity: Effects of prior accidents and incidents on airline's learning. Administrative Science Quarterly, 47: 609-643.

Hynes, T., \& Prasad, P. 1997. Patterns of "mock" bureaucracy in mining disasters: An analysis of the Westray coal mine explosion. Journal of Management Studies, 34: 601-623.

Ichniowski, C., Kochan, T., Levine, D., Olson, C., \& Strauss, G. 1996. What works at work: Overview and assessment. Industrial Relations, 35: 299-334.

Ichniowski, C., Shaw, K., \& Prennushi, G. 1997. The effects of human resource management practices on productivity: A study of steel finishing lines. American Economic Review, 87: 291-313.

LaPorte, T.R., \& Consolini, P. 1991. Working in practice but not in theory Theoretical challenges in high reliability organizations. Journal of Public Administration Research and Theory, 1 (winter): 19-47.

MacDuffie, J.P. 1995. Human resource bundles and manufacturing performance: Organizational logic and flexible production systems in the world auto industry. Industrial and Labor Relations Review, 48: 197-201.

Perrow, C. 1984. Normal accidents: Living with high-risk technologies. New York: Basic Books.

Pfeffer, J. 1998. The human equation: Building profits by putting people first. Boston, MA: Harvard Business School Press.

Reason, J.T. 1997. Managing the risks of organizational accidents. Brookfield, VT: Ashgate.

Roberts, K.H. 1990. Some characteristics of one type of high reliability organization. Organization Science, 1: 160-177.

Roberts, K.H., \& Bea, R. 2001a. Must accidents happen? Lessons from high reliability organizations. Academy of Management Executive, 16: 70-78.

Roberts, K.H., \& Bea, R. 2001b. When systems fail. Organizational Dynamics, 29: 179-191.

Roberts, K.H., Stout, S.K., \& Halpern, J.J. 1994. Decision dynamics in two high reliability military organizations. Management Science, 40: 614-624.

Rochlin, G.I. 1989. Informal organizational networking as a crisis avoidance strategy: U.S. naval flight operations as a case study. Industrial Crisis Quarterly, 3: 159-176.

Rogers, E.W., \& Wright, P.M. 1998. Measuring organizational performance in strategic human resource management: Problems, prospects, and performance information markets. Human Resource Management Review, 8: 311-331.

Rudolph, J.W., \& Repenning, N.P. 2002. Disaster dynamics: Understanding the role of quantity in organizational collapse. Administrative Science Quarterly, 47: 1-30.

Schulman, P. 1993. The analysis of high reliability organizations: A comparative framework. In K.H. Roberts (Ed.), New challenges to understanding organizations: 33-54. New York: Macmillan.

Schulman, P. 2001. Review of J.M. Sanne, Creating safety in air traffic control. Administrative Science Quarterly, 46: 345-348. 
Shrivastava, P. 1987. Bhopal. Cambridge: Ballinger.

Schuler, R., \& Jackson, S. 1987. Linking competitive strategies and human resource management practices. Academy of Management Executive, 1: 207-219.

Starbuck, W.H., \& Milliken, F.J. 1988. Challenger: Fine tuning the odds until something breaks. Journal of Management Studies, 25: 319-340.

Tushman, M.L., \& O'Reilly, C.A. 1996. Ambidextrous organizations: Managing evolutionary and revolutionary change. California Management Review, 38: 8-31.

Vaughan, D. 1996. The challenger launch decision. Chicago: University of Chicago Press.

Vaughan, D. 1999. The dark side of organizations: Mistake, misconduct, and disaster. Annual Review of Sociology, 25: 271-305.

Weick, K.E. 1988. Enacted sensemaking in crisis situations. Journal of Management Studies, 25: $305-317$.

Weick, K.E. 1990. The vulnerable system: An analysis of the Tenerife air disaster. Journal of Management, 16: 571-593.

Weick, K.E. 1993. The collapse of sensemaking in organizations: The Mann Gulch disaster. Administrative Science Quarterly, 38: 628-652.

Weick, K.E., \& Roberts, K.H. 1993. Collective mind and organizational reliability: The case of flight operations on an aircraft carrier deck. Administrative Science Quarterly, 38: 357381.

Weick, K.E., \& Sutcliffe, K.M. 2001. Managing the unexpected. San Francisco: Jossey-Bass.

Weick, K.E., Sutcliffe, K.M., \& Obstfeld, D. 1999. Organizing for high reliability: Processes of collective mindfulness. In B.M. Staw \& R. Sutton (Eds.), Research in organizational behavior, vol. 23: 81-123. Greenwich, CT: JAI Press.

Wright, P. 1998. Human resources-strategy fit: Does it really matter? Human Resource Planning, 21: 56-57.

Wright, P., \& Gardner, T. 2002. Theoretical and empirical challenges in studying the human resources practice-firm performance relationship. In D. Holman, T. Wall, C. Clegg, P. Sparrow, \& A. Howard (Eds.), The New Workplace: People Technology, and Organization, London: Wiley.

Wright, P., \& Sherman, S. 1999. The failure to find fit in strategic human resource management: Theoretical and empirical considerations. In P. Wright, L. Dyer, J. Budreau, \& G. Milkovich (Eds.), Research in Personnel and Human Resources Management (Supplement 4: Strategic Human Resource Management in the $21^{\text {st }}$ Century). Stamford, CT: JAI Press.

Youndt, M.A., Snell, S.A., Dean, J.W., \& Lepak, D.P. 1996. Human resource management, manufacturing strategy, and firm performance. Academy of Management Journal, 39: 836-867. 